\title{
Talent Attraction through Online Recruitment Websites: Application of Web 2.0 Technologies
}

\section{Pratyush Banerjee}

Birla Institute of Technology \& Science (BITS)

Pilani

pratyush.banerjee@pilani.bits-pilani.ac.in

\section{Ritu Gupta}

T A Pai Management Institute

\section{Abstract}

Talent attraction is one of the major challenges for HR managers. With the rise of online recruitment channels, the number of applicants for a given job vacancy have increased substantially. In addition, the time taken in finding the right talent from the huge pool of applications has increased significantly, adding up to the hiring cycle. In today's competitive labour market, employers need to highlight their brand image to prospective job-seekers, so that there is higher chance of recruiting the best talent that fits their manpower requirement. In this paper, an attempt is made in investigating that to what extent web 2.0 technologies such as podcasts, blogs and online employee testimonials may enhance the employer's brand value in the eyes of employed professionals. A multi-group moderated mediation analysis is conducted with 361 working professionals who are active online recruitment platform users. The analysis helps establish the effect of the perceived quality and credibility of career websites on job-seekers' perception about the employer and on their subsequent application intention. The findings reveal positive effect of video podcasts and realistic employee testimonials presented through third party blogs on job-seekers' perceived quality and credibility of the job advertisement. This phenomenon is reflected in their heightened attraction for the employer and eventual intention to apply for jobs at the firm.

Keywords: E-recruitment; Realistic Job Preview; Blog; Podcast; Employer Branding; Talent attraction

\section{Introduction}

Technology has completely changed the traditional human resource (HR) functions. One of the most affected functions is the process of employee recruitment. Organizations today extensively use internet technology to invite applications in a cost and time efficient manner for searching and hiring talented individuals. This phenomenon is called electronic recruitment, also known as e-recruitment (Maurer \& Liu, 2007; Maurer \& Cook, 2011). There are several platforms of online recruitment, for example company's career website, online newspaper's career column, e-recruitment portals (also known as third party e-recruitment service provide or job boards) and professional job networking sites used for job postings such as LinkedIn (Borstroff, Marker \& Bennett, 2007; Walker, Field, Giles, Armenakis, \& Bernerth, 2009).A decade ago, an astounding number of almost 110 million jobs and 20 million resumes were posted on various job portals such as Monster in United States of America (USA) alone (Maurer \& Liu, 2007). Over the years, these numbers have been exponentially growing. By 2017, there were 52 million registered job-seekers inNaukri.com, the largest e-recruitment job search engine in India (Naukri Job Speak, 2017; Monster Employment Index, 2017). 
E-recruitment has emerged as a highly cost-effective solution compared to traditional recruitment channels such as print advertisement, walk-in interviews and campus placement. For example, Dow Chemical's reduced its hiring cycle from 90 to 34 days and reduced its cost per hire by $26 \%$ by adopting e-recruitment practices (Maurer \& Liu, 2007). Majority of the Fortune 500 organizations have moved to e-recruitment and selection processes (Chapman \& Webster, 2003). With the advent of social media, there is further scope now to save more time and money through e-recruitment strategy (Vicknair, Elkersh, Yansey, \& Budden, 2010). In India, third party e-recruitment service providers such as Naukri and Monster have created a strong presence in the job market (Doh, Stumpf, Tymon, \& Haid, 2008; Kumari, Bhat, \& Pandey, 2010). There has been significant reduction in costs incurred by Indian firms using erecruitment media, costing them approximately $80 \%$ less than traditional recruitment activities (Tyagi, 2012).

The credibility of online job advertisements has been questioned by several researchers, as the findings from empirical studies indicate that job-seekers view traditional media such as employee referrals and campus placements as more credible sources for job advertisements than modern channels such as job portals and career websites (Cable, Aiman-Smith, Mulvey \& Edwards, 2000; Cable \& Yu 2006). One reason for this negative attitude may be due to the over utilization of employee testimonials in e-recruitment which specifically portray only the positive side of the work place (Reeve, Highhouse, \& Brooks, 2006). Another reason behind the poor acceptance of e-recruitment channels may be attributed to lack of appeal of website designs. There is strong evidence that poorly designed websites may have a negative effect on applicant's attitude towards the portal in turn affecting their will to apply for the jobs posted on such websites (Cable \& Yu, 2006; Maurer \& Liu, 2007).

In the current study, the objective is to explore how the credibility of the e-recruitment advertisement and the quality of the e-recruitment website influence the working professional's attitude towards e-recruitment websites, thus affecting their perceived attractiveness towards the employer and consequently their intention to apply for that job. Specifically, the study explores whether the perceived quality of the e-recruitment advertisement, which in turn affects organizational attractiveness, can be influenced by providing innovative corporate preview of the firm such a streaming podcast, compared to a traditional textual description. This study also explores the impact of realistic employee testimonials in place of positively framed ones, to see if perceived credibility of the job advertisements through corporate career websites can be enhanced. Additionally, this study probes the possibility of posting online job-related information of a corporate entity through a third-party blog platform to investigate whether this may further enhance the credibility of the information projected about the organization through online job advertisements. Finally, this study tests the implication of such perceptions on the intention of job seekers to apply for a certain job advertisement belonging to a particular e-recruitment channel.

\section{Literature Review: Web 2.0 and E-recruitment}

Majority of the studies in e-recruitment have focused on the issues surrounding the design adequacy of e-recruitment websites (Cober, Brown \& Levy, 2004). Many researchers have explored the factors affecting perceptions of applicants (job-seekers) towards the credibility of messages propagated through e-recruitment websites (Dineen, Ash \& Noe, 2002; Borstroff et al., 2007; Allen, Mahto, \& Otondo, 2007; Van Hoe \& Lievens, 2007). 
Previous studies have found that source credibility is directly related with job offer acceptance (Fisher, Ilgen \& Hoyer, 1979). It has been found that realistic job previews (RJPs) given to the job seekers at the time of recruitment enhance the commitment level of employees (Barksdale, Bellenger, Boles, \& Brashear, 2003). RJPs have potential to disseminate realistic information about a context, here applicants are shown both positive and negative aspects of the job in the organizational context, it increases their trust on the organization's integrity and honesty (Dugoni \& Ilgen, 1981; Meglino, Ravlin, \& Denisi, 1997; Breaugh \& Starke, 2000). There are only a few studies exploring the effect of employee testimonials on applicant's attitude in erecruitment context (Van Hoye \& Lievens, 2007). Hence, there exists a lacuna in understanding how job-seekers perceive realistic employee testimonials put up in online career websites. It is suggested that RJPs shared on web will make job information more credible than traditional text-based previews (Meglino et al., 1997). As these reviews will be interactive and unbiased, they may be shared on neutral medium of communication. However, there is lack of empirical validation against such claim.

There is a big dilemma about what may be the best way for enhancing credibility of job-related information to jobseekers. The dilemma is mainly centred around whether the online job advertisements on company owned websites like corporate career portals are sufficient or these advertisements should be posted on neutral cyber platforms (Walker et al., 2009). In this regard the rise of unbiased end user driven platforms such as Glassdoor (Mallon, 2017) have opened scope of highlighting company image in a more objective manner. Web 2.0 technology (Gokhale \& Chandra, 2009), such as blogs, internet chat rooms and social networking websites have been observed to influence consumer decision to buy a certain product online (Koufaris, 2002) or for adoption of online banking (Adapa \& Cooksey. 2013).

Web 2.0 technology has found its application in e-recruitment as well, though the adoption is at a slower rate (Russell, 2008). There is strong empirical evidence regarding the impact of website design features such as colour, layout, and page loading time and customized search options on perceptions about quality of the website (De Goede, van Vianen, \& Klehe, 2011). Empirical tests in advertisement research have demonstrated that information delivered in audio-visual mode is considered more engaging and enriching than that delivered in text mode (Walker et al., 2009; McGowan, 2010). In e-recruitment context, Banerjee (2016) conducted an experiment with college students about to enter the job market regarding the impact of various website manipulations such as RJPs, Blogs and use of Podcasts. His study showed that job-seekers assessed career websites featuring RJPs, Blogs and Podcasts with greater trust and more attention than the websites lacking in one or more of these features. However, the research was limited to only college graduates and could not be validated for working population.

\section{Hypothesis formulation}

\subsection{Perceived quality of website $\rightarrow$ Applicant's attractiveness of the employer brand}

A website's overall usefulness and user-friendliness encompasses the quality of the website (Loiacano, Watson, \& Goodhue, 2007; Knight \& Burn, 2011). In a study conducted in the US, it was found that websites designed poorly cost $\$ 30$ million per day to corporate career portals (Maurer \& Liu, 2007). Website design features may affect perceptions about quality of the 
website; these features include colour, layout, page loading time and customized search options amongst others (Howardson \& Behrend, 2014).

Further, Cognitive Load Theory (Chandler \& Sweler, 1991) emphasizes that human beings can process information better if it is presented to them in a graphic manner. In e-recruitment research, the impact of audio-visual mode of information delivery as a means of enhancing employer attractiveness has not been explored much (Banerjee, 2016). A website can make the employer or the job position really attractive, if the audio-visual tools such as podcasts are used to present the job as a desirable career opportunity for the applicant (McGowan, 2010).

Using Brand Equity Theory (Aaker, 1997), it may be deduced that positive perceptions of quality of a firm's e-recruitment website can positively influence job seeker attitude towards the firm as a prospective employer. Learning a lesson from brand equity theory, it can be inferred that if job seekers receive cues about higher perception of website quality through audio-visual corporate previews, then job seekers will feel attracted towards the organization as a prospective employer. Finally, the Theory of Planned Behavior (TPB) (Ajzen, 1991; Lin, 2010), states that the decision to engage in a particular behaviour is the result of a rational process, which in the case of online job-seekers, involves the job seeker's reasoning that a firm has a willingness to meet the diverse search demands of the job seeker through its website. As a result, job-seekers may develop a positive attitude towards the firm's career website in the form of more positive perceptions of the employer brand (Ambler \& Barrow, 1996). This eventually will be reflected in their actions such as feeling attracted towards the firm and in a higher intention to apply for jobs through that site (Ajzen, 1991). Therefore, we hypothesize

H1: A positive perception of quality of e-recruitment website will significantly increase perceived attractiveness about the employer for online job-seekers.

\subsection{Perceived credibility $\rightarrow$ Applicant's attractiveness of the employer brand}

Trust formation in an online platform requires the latter to project authentic and unbiased information to the users (Bewsell, 2009). Employee testimonials are being used increasingly to enhance credibility of the recruitment advertisements. It also helps in providing applicants an internal viewpoint about the work life at the organization (Dineen et al., 2002; Cable et al., 2000). Applicants find employee testimonials informative and indicative of their expectations from the work place thus making them apply for the job.

However, use of RJPs in e-recruitment context has been relatively less. RJPs have evolved from the realistic information hypothesis which indicates that, when applicants are shown both positive and negative aspects of the job in the organizational context, it increases their trust on organizations integrity and honesty (Dugoni \& Ilgen, 1981; Petty, Casmer, Haugtvedt, \& Cacioppo, 1987). It also follows from media credibility theory (Cable \& Yu, 2006) and the Yale Persuasive Communication Model (Oskamp, 1977) that if the source of any information is considered to be trustworthy, then the receivers would positively appraise the information. RJPs provide information which breaks the conventions of employer branding by preaching about both the positive and negative aspects of a workplace. Thus, on the overall level of trustworthiness, such testimonials may be considered as more credible than testimonials which appear to be fabricated to portray only good things about a firm (Popovich \& Wanous, 1982).

Based on Signalling Theory (Gregory, Meade, \& Thompson, 2013), it may be further opined that the trust cues that job-seekers may receive due to realistic employee testimonials on 
neutral platforms (e.g., blogs) will increase their respect for the employer and make them more inclined towards considering the firm as a potential employer. Therefore, it may be hypothesized that

H2: Positive perception about credibility of information shared through online career websites will significantly increase perceived attractiveness about the employer for online job-seekers.

\subsection{Mediating role of organizational attractiveness}

Further, Theory of Reasoned Action (TRA) (Ajzen, 1991) suggests that in case of systematic information processing, job-seekers may first make judgment about the credibility of the message and the quality of presentation of the message. After this, the next stage of cognition will involve perception regarding the attractiveness of the firm as a potential employer. Following this, the applicants will form their overall intention to apply for the job (Pfieffelmann, Wagner, \& Libkuman, 2011). Therefore, there is a possibility that organizational attractiveness will mediate the relationship between perceived quality and intention to apply and the relation between perceived credibility and intention to apply.

H3a: Organizational attractiveness will mediate the effect of perceived website quality on job-seekers' intention to apply for jobs online.

H3b: Organizational attractiveness will mediate the effect of perceived credibility of online job advertisements on job-seekers' intention to apply for jobs online.

\subsection{Moderating effects of website design manipulations}

Signalling theory allows us to explore that depending on the nature of preview-mode, testimonial-type and testimonial-source, job-seekers will have different cues to process jobrelated information. Hence, the treatment conditions can be considered as possible moderators in the linkage for the path between perceived quality and organizational attractiveness and the path between perceived credibility and organizational attractiveness.

\subsubsection{Moderating effect of preview-mode}

Previous research has shown that audio-visual media is a better channel to persuade audience compared to oral or booklet-based channels (Popovich \& Wanous 1982). Baddeley's (1992) cognitive load theory points in the same direction, where it is explained why information presented in different modes (some through audio, some through video mode) leads to easier interpretation of the message by the receiver. However, it has not been examined, whether use of video podcasts can help in increasing the appeal of online job advertisements. Specifically, it is important to understand how using video-based information delivery styles increases the richness of the e-recruitment media thus enhancing credibility perceptions of the message. It has also been observed that the working memory of human beings consists of a video-spatial sketchpad and a phonological loop which can retain visual and audio stimuli independently (Chandler \& Sweller, 1991; Baddeley, 1992). Thus, information distributed in parts through audio and visual channels such as in live streaming videos (podcasts and vodcasts) can be more helpful for processing of information when presented as a whole.

Communication channels which, permit timely feedback (e.g., real-time exchange of messages), convey multiple language cues (e.g., words, facial expressions, body posture), allow tailoring of messages to personal circumstances (e.g., customized to the needs of a recipient), and provide language variety (e.g., written text, charts and graphs, verbal expression) are referred to as rich media (Daft \& Lengel, 1986). As per the media richness 
theory (Daft \& Lengel, 1986; Cable et al., 2000), synchronous media such as face-to-face oral communication, telephonic communications etc. are richer than asynchronous media such as mail correspondence or information in a webpage (Cable \& Yu, 2006).

In earlier studies, textual communication has been found to be the least rich medium of communication (Zusman \& Landis, 2002; Cober et al., 2004; Cable \& Yu, 2006). Previous studies have shown that pictures strongly enhance and reinforce information about an organization's values (Cober et al., 2004) and can impact memories more effectively than text. Moreover, the use of pictures in addition to text increases the viewer's cognitive awareness, leading to an increase in attention to the information provided (Daft \& Lengel, 1986). Presenting corporate previews through video podcasts/vodcasts can have a more lasting effect on positive employer brand perceptions and consequently on better perceptions of website aesthetics. Further, such audio-visual previews can be easier to understand compared to the current practice of textual previews. In one study by Adams, Morris and Van Scotter (1999), face-to-face communication was found to be the best attention grabber, followed by video with audio, then audio only and followed by text only.

On the basis of the above argument, it is opined that the relationship between perceived quality and intention to apply will be moderated by the type of preview-mode used by the firm to describe its corporate profile to prospective applicants. An audio-visual profile will create a better perception regarding the website's quality, and this may enhance the richness of the medium and make the message appear to be more believable (Walker et al., 2009). Consequently, it will trigger a positive perception of brand equity in the minds of the jobseeker thus, creating a higher sense of firm attractiveness. Therefore, we posit that,

H4a: The relationship between perceived quality and organizational attractiveness will be moderated by corporate preview mode such that the effect will be higher for audio-visual preview as compared to that for text-based preview.

H4b: The relationship between perceived credibility and organizational attractiveness will be moderated by corporate preview mode such that the effect will be higher for audio-visual preview as compared to that for text-based preview.

\subsubsection{Moderating effect of testimonial-type}

Online job ads may find it difficult to establish a sense of realism in their content to attract potential employees. To counter such effect, organizations have tried to use employee testimonials in e- recruitment ads to give jobseekers a peep into the real work environment. However, such practices have been limited to using only positive feedback about the workplace from the employees (Breaugh \& Starke 2000). RJPs, which have been used extensively in traditional recruitment research, have been completely neglected in erecruitment research (Strohmeyer, 2007; Wolfswinkel, 2009).

Since the content of a webpage can be manipulated by the firm owning the website, therefore, if jobseekers find only good feedback given by employees about their organization in the testimonials, they may consider such feedback less credible and lose the desire to apply for job in that organization (Young \& Foot 2005). It has also been found that people consider any information as trustworthy if they receive information that is different from what is expected by them (Breaugh \& Starke 2000). In this regard, RJPs definitely provide unexpected information about a job. Similarly, it is being reasoned that if the testimonial is realistically framed, it will create a higher perception of quality and credibility as per Technology 
Acceptance Model (TAM) and Yale Persuasive Communication Model (YPCM) (Oskamp, 1972; Phillips, 1998). This may create a greater sense of appreciation regarding the honesty of the firm and indirectly make the firm more attractive (Petty et al., 1987; Cable \& Yu, 2006). Therefore, it is proposed that,

H5a: The relationship between perceived quality and organizational attractiveness will be moderated by testimonial-type such that the effect will be higher for realistically framed testimonial as compared to that for positively framed testimonial.

H5b: The relationship between perceived credibility and organizational attractiveness will be moderated by testimonial-type such that the effect will be higher for realistically framed testimonial as compared to that for positively framed testimonial.

\subsubsection{Moderating effect of advertisement source}

Due to the possibility of content manipulation by the website owner in case of e-recruitment, it has been time and again observed that job seekers have relied less on job related information posted online and have preferred more traditional media to seek such information. Such user behaviour can be interpreted through the source credibility framework (Van Hoye \& Lievens 2007), which posits that more credible information sources are considered more persuasive in changing attitudes as well as behaviours. In e-recruitment context, this theory suggests that job seekers perceive credibility of different recruitment sources based on the level of neutrality of the sources. This is because, the more neutral a recruitment source, less is its motivation to explicitly promote the recruiting firm. Therefore, company independent sources of erecruitment should be considered as more credible than company dependent sources (Van Hoye \& Lievens 2005; 2007).

Earlier e-recruitment was conducted primarily through company-dependent sources such as job boards (e.g., Monster.com) that post job descriptions and specifications for organizations for a fee or via organizations' official websites. In recent years, a new wave of internet revolution has taken place with the advent of Web 2.0 technology (blogs, chat-rooms, social networking sites etc.), which has made the cyber experience of users more interactive and realtime (Russell, 2008). Nowadays, we have several WEB 2.0 enabled web-based platforms such as social networking websites (MySpace, Facebook etc.) being used by head-hunters to recruit passive job seekers and independent blogs such as Glassdoor (www.glassdoor.com) where ex and current employees can post their testimonials about their previous and current workplaces respectively (Russell, 2009). Such platforms have the advantage over company owned websites for being considered as credible, because such media are free from any outside corporate influence and generally firms do not have control over the content of such websites (Van Hoye \& Lievens 2007).

Employee testimonials are an important means, which organizations can use in their website design features to portray their culture. Fazio and Zanna (1981) found that jobseekers like testimonials because they are first-hand personal accounts of the organizational culture and anecdotal evidence indicates that testimonials are highly persuasive in recruitment contexts (Highhouse, Hoffman, Greve \& Collins, 2002). Cober et al. (2004) also suggested the positive aspect of using employee testimonials citing the fact that such testimonials provide a human touch, enhancing feelings of identification with the hiring organization. Web 2.0 platforms such as web blogs have opened a new avenue for communicating free thoughts to the masses in this digital age. Also, if the firm does not provide the testimonials themselves but direct the 
job-seekers to third party blogs to view the testimonials, it may likewise create a greater sense of authenticity and trustworthiness for the message which again follows from TAM and YPCM (Petty et al., 1987; Knight \& Burn, 2011). This leads to the following hypotheses,

H6a: The relationship between perceived quality and organizational attractiveness will be moderated by advertisement-source such that the effect will be higher for company-independent source as compared to that for company dependent source of advertisement.

H6b: The relationship between perceived credibility and organizational attractiveness will be moderated by advertisement-source such that the effect will be higher for company-independent source as compared to that for company dependent source of advertisement.

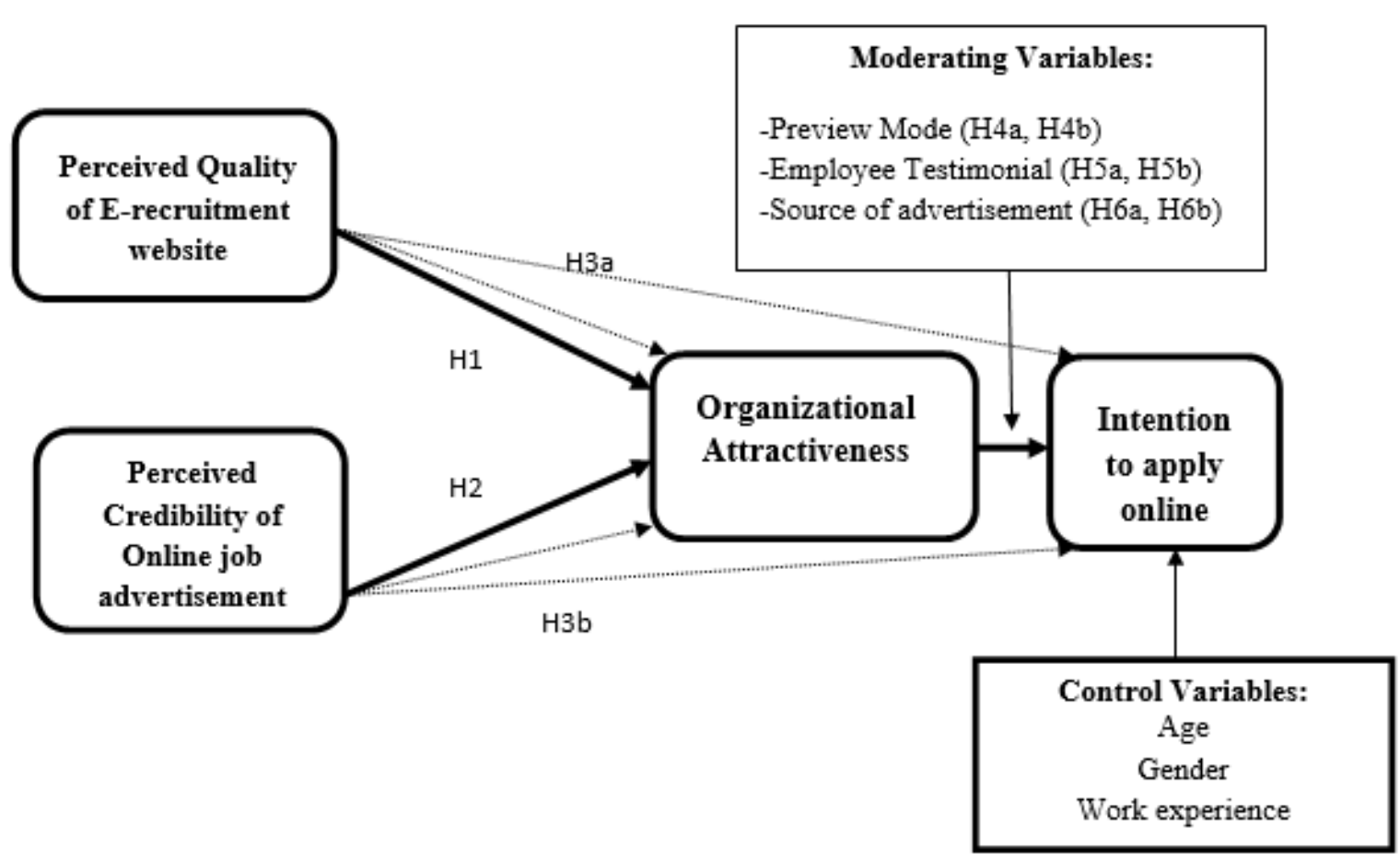

(Note: The moderation hypotheses are represented in a combined manner)

Figure 1: Research Model

\section{Research Methodology}

An experimental design was adopted to test whether different types of corporate previews, testimonials and ad-sources can have different effect on the job-seekers' desire to apply for job. For this, six different websites were created depicting a career webpage of a fictitious firm in six different styles with the help of a professional web-development agency.

The authors used an open-source online website design service provider 'Webs' (www.webs.com) to create a fictitious firm, 'Eco-tech Concepts and Solutions' (henceforth referred to as ECS) website. The basic website development required an understanding of what a career website of an organization must look like to be considered good. For this purpose, the authors decided to take cue from both published studies on website content in recruitment context as well as through a content analysis of some of the best companies operating in India. A coding structure was developed by carefully scrutinizing earlier content 
analyses of job-related websites such as the studies from Koong and colleagues (2002), Cober and associates (2004), Young and Foot (2005), Yoon Kin Tong and Sivanand (2005), and Banerjee and Gupta (2016).

These insights were used to design the prototype of a website having all possible features of one operating in real world so that the fictitious company looks real from similar industry context (Banerjee \& Gupta, 2016). Like any website may have multiple web-pages, this website also contained five separate web pages, namely Homepage, About Us, Services, Join Us and Contact Us. The 'Homepage' was used to describe the business aspect of the company. The 'Services' page highlighted four different verticals of the firm. The 'Contact us' page indicates the location of the head-quarter of the company and there was provision for customer query.

The 'Join Us' page of the six different websites featured different manipulations. These manipulations include positive or realistic testimonials, a snapshot of which is provided in figure 2 which is showing RJP type testimonials (pros and cons) from the website 2), presence of testimonials across websites or through a fictitious external blog (named insideoffice) which was linked with the firm's 'Join Us' page which is shown through figure 3 depicting an external blog in the website 4). The comments posted by employees about the company on this blog could be viewed by anyone and did not require any registration. This blog was created keeping in mind similar platforms like Glassdoor and Quora which are known for hosting anonymous feedback by ex-employees of firms.

A manipulation was also made in the 'About Us' page, where two different modes of corporate preview- text based and audio-visual have been created (Figure 4: websites 5 and 6). The audio-visual manipulation was created using 'Windows Moviemaker' software. The content for these videos were picked from videos available online either on company websites or YouTube, in order to maintain realistic feel of the company. It was ensured that none of the video clippings used could be used to identify any actual company from the video used through suitable pre-tests.

The employee testimonials were designed to eliminate gender bias, by having one male and one female narrating their experience about the company in positive light for one website. In another version, employees were seen talking about the pros and cons of working at the ECS. Three web development experts were also invited to give their opinion on the web development and to verify the website design. Finally, the authors had six different websites, each with different combinations of preview-mode, testimonial type and testimonial source which were used as treatments in the following experiment. 


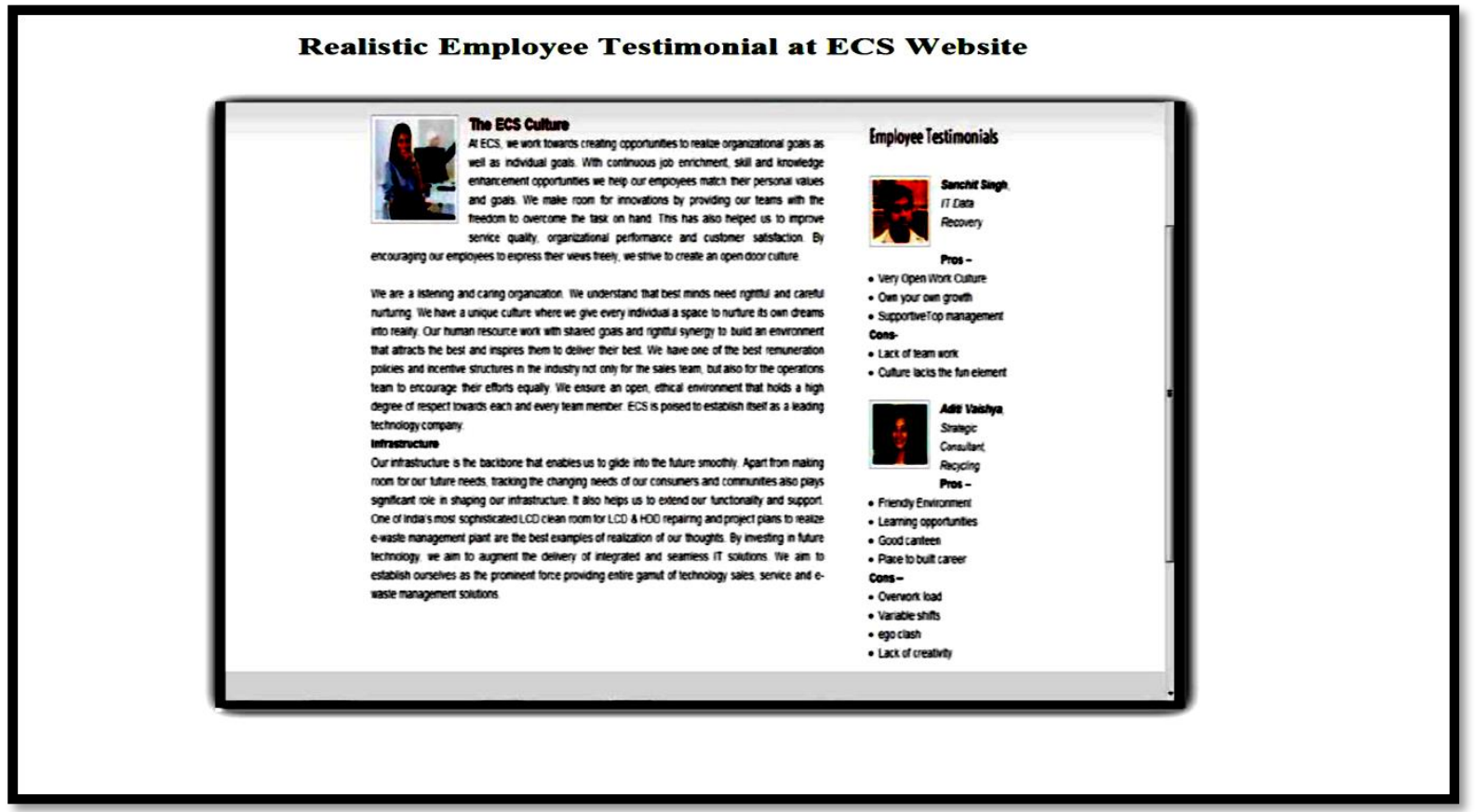

Figure 2: Realistic employee testimonials as depicted in Website 2

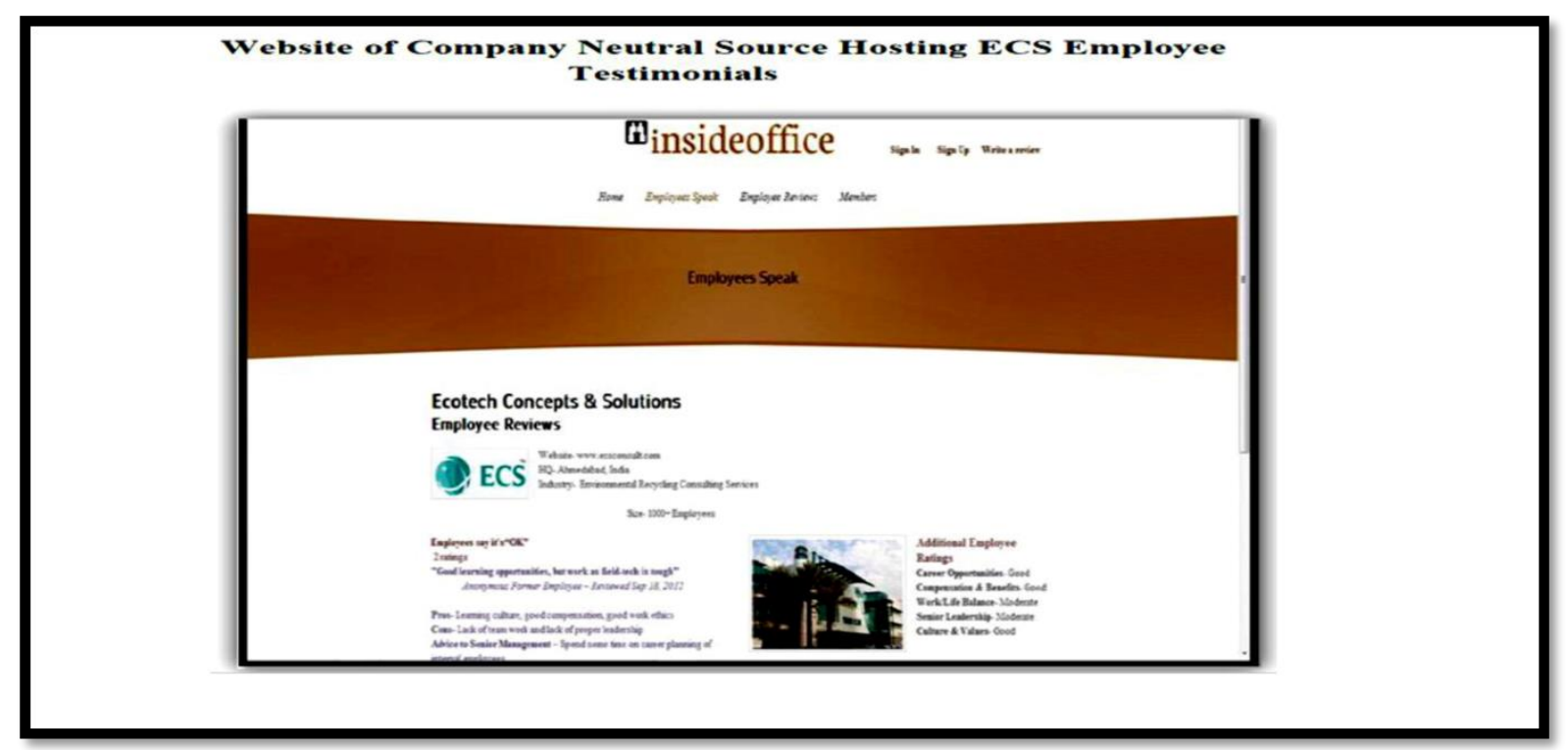

Figure 3: The Website 4 showing an external blog where ECS Employee testimonials can be accessed 


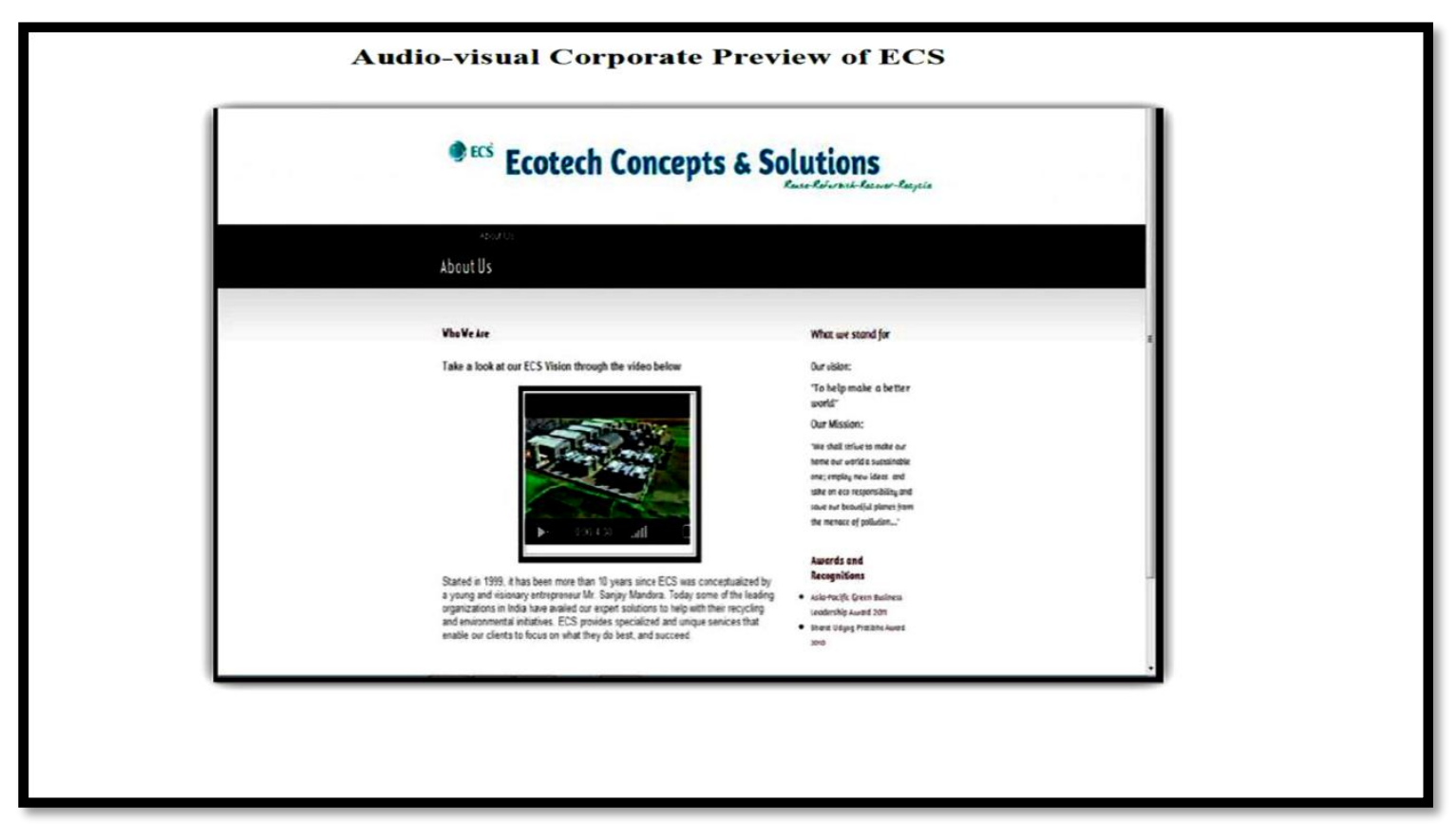

Figure 4: Website 5 showing audio-visual streaming video tour preview of organization

\subsection{Measurement of variables}

A survey questionnaire based on 5-point Likert-type scale was used to collect data on the variables of interest for this study. The scale items were derived from existing valid psychometric instruments which have been repeatedly used by past researchers in related study contexts. The scale reliabilities were observed to be above 0.7 in all the cases (Nunnally, 1978), thus giving evidence of good reliability of the indices.

Perceived job advertisement credibility is measured using a scale to measure perception of credibility of online information developed by Johnson and Kaye (2004). This is a 4 item Likert type scale with feedback option ranging from $1=$ not at all believable and $5=$ very much believable. Example of a scale item is 'how believable did you find the job-related information presented in the Join Us section?'

Perceived website quality is measured using the perceived design quality subscale of WEBQUAL 3.0 developed by Barnes and Vidgen (2001). This subscale measures generic perception regarding the design and layout of a website. It is an eight-item scale, which uses five-point Likert $1=$ strongly disagree and $5=$ strongly agree, to capture responses.

Organizational attractiveness is measured using the 4 item 5-point Likert scale created by Highhouse et al., (2002). A sample item is "This company is attractive to me as a place for employment".

Intention to apply is measured using a 3 item 5-pointscale developed by van Birgelen, Wetzels and van Dolen (2008). A sample item is "I would like to accept a job offer from this company".

Control and demographic variables: Age, gender, and work experience have been controlled in the study.

\subsection{Data Collection}

Data was collected using a web-based survey with job-seekers who have already been working for the past 1-2 years and have registered their details in various popular third-party job 
portals in India such as Naukri.com, Monster.com etc. The criterion for selection was that the registered users should have been actively involved in online job search during the time of the survey (indicated through the frequency of visit/ updates made in their profile). Job-seekers registered with either Naukri or Monster India or both with either or both engineering and MBA backgrounds and with at least one year of experience were identified as the target population. This choice was justified by the fact that Naukri and Monster cater to the largest contingent of online recruitment service users in India. The email contact of the registered users in Naukri and Monster could be accessed through the co-operation of third-party recruiters who have employer login access to these websites. In order to maintain the confidentiality of the individuals, only a list of email-ids was provided by the third-party recruiters, who have either or both MBA and engineering degrees and have worked for at most 2 years. The final list included 1425 email-ids of registered e-recruitment users.

The respondents were then contacted through a formal email briefing them about the purpose of the study and then requesting them to take part in the survey. Random allocation technique was used to ensure parametric estimation of results (Forder, Gebski, \& Keech, 2005). In total, 361 recipients responded to the invitation and agreed to take part in the study. Then using random number table, the respondents were assigned to six different groups of approximate size of 60 members. The link to the six different websites along with a short online survey was then sent to the randomly selected groups to achieve randomized allocation. The online questionnaire was designed with a very simple interface so that participants can understand the necessary actions to be able to complete the survey. All questions were mandatory, i.e., unless respondents answered all the queries, the questionnaire could not be submitted. The completed responses which were submitted got recorded in an excel file. Hence, there was no case of missing data.

Approximately $64 \%$ respondents were male and $75 \%$ were in the age group of 20-25 years. Respondents were mostly graduate $(44.5 \%)$ and postgraduate $(51 \%)$ with MBA and Engineering degrees accounting for $80 \%$ of the educational qualification. Over $60 \%$ respondents reported work experience in the range of 1-2 years while another $30 \%$ reported work experience of 2-3 years. Nearly $68 \%$ respondents replied that they have been actively involved in online job search process in the past 1-3 years. Further, $98 \%$ respondents replied that they have registered profiles in Naukri.com while $90 \%$ replied that they have profile in Monster.com, followed by Timesjobs.com at a distant third (52\%).

\subsection{Data Analysis}

Overall, the descriptive statistics gave indications that the respondents in our sample had fairly high perceptions of quality of the website (Mean=3.515, SD=1.1082) and credibility (Mean=3.368, SD=1.1352). Perceived organizational attractiveness (Mean=3.798, SD=0.9071) and intention to apply (Mean=3.471, SD=1.0464) were also high in the individuals (refer to table 1).The correlation matrix (Table 1) gives indications that perceived credibility is positively correlated with perceived quality $(\mathrm{r}=.420)$, organizational attractiveness $(\mathrm{r}=.386)$ and intention to apply $(\mathrm{r}=.537)$. Perceived quality is also positively correlated with attractiveness $(\mathrm{r}=.356)$ and intention to apply ( $\mathrm{r}=.651)$. 


\begin{tabular}{|c|c|c|c|c|c|c|c|}
\hline Name of construct & M & SD & $\begin{array}{c}\text { Cronbach } \\
\text { Alpha }\end{array}$ & 1. & 2. & 3. & 4. \\
\hline 1.Perceived Credibility & 3.3684 & 1.13529 & 0.94 & 1 & .820 & .386 & .937 \\
\hline 2. Perceived Quality & 3.5152 & 1.10826 & 0.96 & .820 & 1 & .356 & .851 \\
\hline $\begin{array}{l}\text { 3. Perceived Organizational } \\
\text { Attractiveness }\end{array}$ & 3.7978 & .90713 & 0.94 & .386 & .356 & 1 & .431 \\
\hline 4. Intention to Apply & 3.4709 & 1.04638 & 0.91 & .937 & .851 & .431 & 1 \\
\hline
\end{tabular}

* Correlation is significant at the 0.01 level (One-tailed).

Table 1: Descriptive Statistics and Correlation Diagnostics

Organizational attractiveness is found to have a positive correlation with intention to apply $(\mathrm{r}=.431)$. Cronbach Alpha values are all above 0.7 (Nunnally, 1978) indicating good reliability of the scales. A covariance based structural equation model (SEM) is estimated to assess the hypothesized relationship (refer to figure 5). The fit of the structural model is acceptable, with $\chi^{2}(77)=115.612(p<.01)$, goodness of fit index $(\mathrm{GFI})=0.919$, comparative fit index $(\mathrm{CFI})=0.989$, incremental fit index $(\mathrm{IFI})=0.923$ and root mean square error of approximation (RMSEA) $=$ 0.016. CMIN/df is 1.501 .

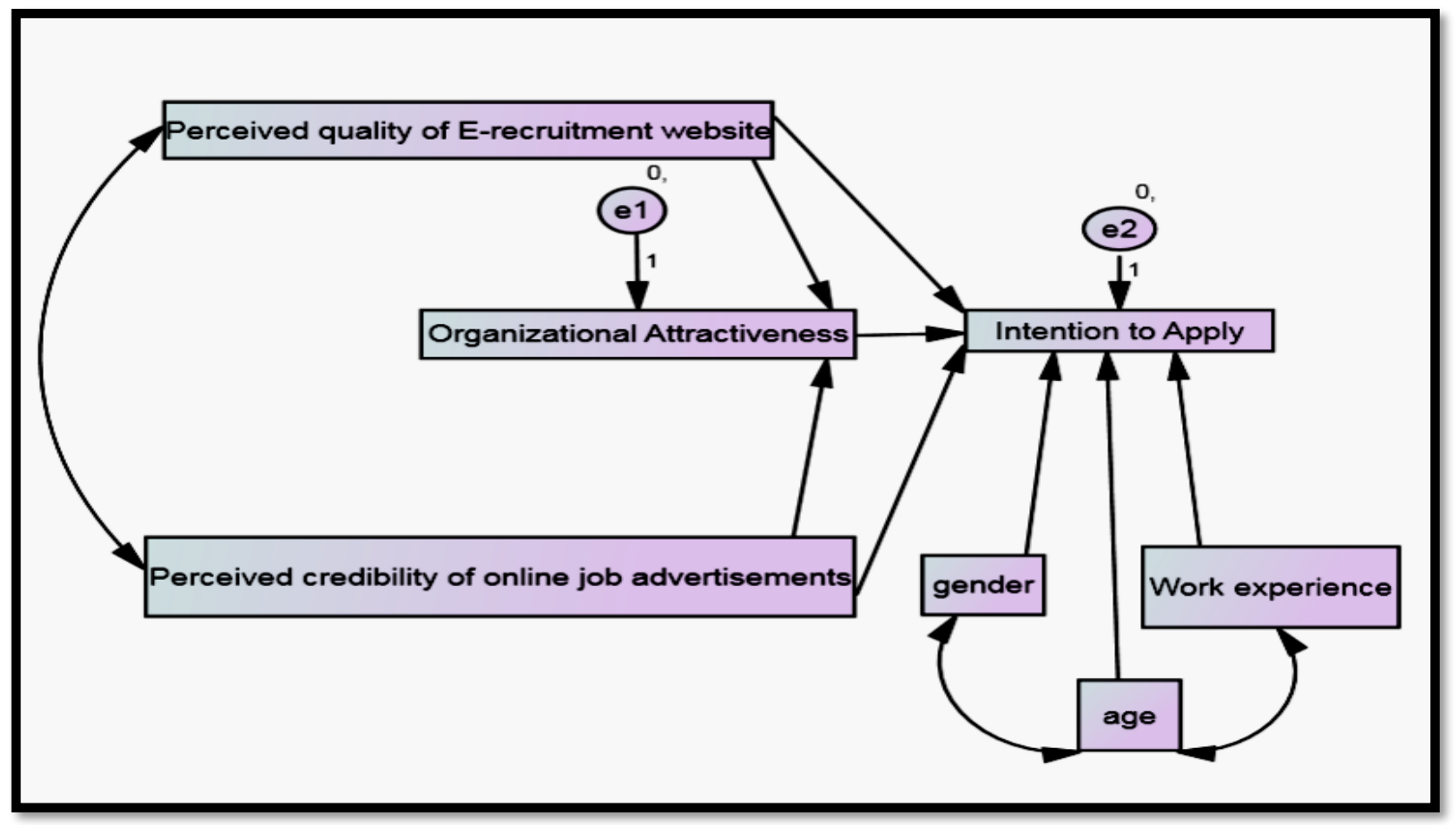

(Note: For each group, the $\beta$ values are different; hence the coefficient values are not reported here)

Figure 5: SEM based converged model for multi-group moderated mediation analysis

Based on these results, the measurement model indicates an acceptable model fit of the data (Hair, Anderson, Tatham, \& Black, 2008). Consistent with the different cut-off criteria provided in the literature (Jöreskog, 1993; Hu \& Bentler, 1999), it is concluded that the hypothesized causal model is within the acceptable range of all the fit statistics. The control variables, namely, gender $(\beta=0.009, p>0.10)$, age $(\beta=-0.10, p>0.10)$ and work experience $(\beta=-$ $0.027, \mathrm{p}>0.10$ ) were all observed insignificant in affecting job-seekers' intention to apply to 
online job advertisements. Perceived quality of website $(\beta=0.331, \mathrm{p}<0.001)$ and perceived credibility of online job advertisement $(\beta=0.566, \mathrm{p}<0.001)$ are observed to have positive effects on organizational attractiveness, thus providing support for hypotheses 1 and 2. For testing hypothesis 3, a mediation analysis was conducted.

\subsection{Results from mediation analysis}

A mediation analysis is conducted using bootstrapping technique (Hayes, 2009; Lowry \& Gaskin, 2014) in SEM to test whether firm attractiveness mediates the relationship between perceived quality of website and intention to apply and between perceived credibility of online job advertisement and intention to apply. The direct effect of perceived quality of website is found to be significant on intention to apply $(\beta=0.331, \mathrm{p}<0.001)$. When the mediator is introduced, then the direct effect of perceived quality on intention to apply continues to be significant $(\beta=0.143, \mathrm{p}<0.001)$. Perceived website quality also had a positive effect on firm attractiveness $(\beta=0.241, p<0.001)$, while attractiveness significantly predicted intention to apply $(\beta=0.784, \mathrm{p}<0.001)$. Therefore, a firm's attractiveness acted as a partial mediator in this context, thus providing partial support for hypothesis 3a. Perceived credibility of job advertisement also demonstrated direct effect $(\beta=0.566, p<0.001)$ on intention to apply. When the mediator was introduced, the path from predictor variable to mediator was also significant $(\beta=0.669, \mathrm{p}<0.001)$, as was the path from mediator to predictor $(\beta=0.784, \mathrm{p}<0.001)$. But the path from predictor to outcome variable became insignificant $(p>0.10)$. Therefore, organizational attractiveness acted as a full mediator in this case, and thus hypothesis $3 \mathrm{~b}$ received full support.

\subsection{Results from moderated mediation analysis}

A moderated-mediation analysis was conducted using the procedure outlined by Preacher, Rucker and Hayes (2008) and by Lowry and Gaskin (2014) to test the hypotheses 4, 5 and 6. Moderated mediation is defined as 'a mediated effect that varies across levels of a moderator, either on the path from the independent variable to the mediator or from the mediator to the outcome variable' (Edwards \& Lambert, 2007; Ng, Ang, \& Chan, 2008).In this case, we expected that the path from perceived quality and perceived credibility to organizational attractiveness will be moderated due to different types of preview-mode, testimonial-type or testimonial-source.

From Table 2, it can be observed that depending on the type of corporate preview-mode, the nature of mediating effect of organizational attractiveness on the relationship between perceived quality of e-recruitment website and job-seekers' intention to apply changes from partial to full mediation. Therefore, preview-mode type moderates the mediating effect and the indirect effect is also more in case of audio-visual preview (indirect $\beta=0.189, p<0.01$ ), suggesting that this mode of preview has more impact on intention to apply than text preview (indirect $\beta=0.148, \mathrm{p}<0.05$ ). Therefore, hypothesis $4 \mathrm{a}$ received full support. With respect to the type of testimonial, we did not observe any change in mediation type, which indicated that testimonial type did not moderate the mediating effect of organizational attractiveness on the perceived quality-intention to apply relationship. 


\begin{tabular}{llcccc}
\hline $\begin{array}{l}\text { Design } \\
\text { Manipulations }\end{array}$ & $\begin{array}{l}\text { Level of } \\
\text { Moderation }\end{array}$ & $\begin{array}{c}\text { Perceived Quality } \rightarrow \text { Organizational Attractiveness } \rightarrow \text { Intention to Apply } \\
\text { PQ } \begin{array}{l}\text { Intention } \\
\text { (without } \\
\text { mediator OA) }\end{array}\end{array}$ & $\begin{array}{c}\text { PQ } \rightarrow \text { Intention } \\
\text { (with } \\
\text { mediator OA) }\end{array}$ & $\begin{array}{c}\text { Total Indirect } \\
\text { Effect }(\beta)\end{array}$ & $\begin{array}{c}\text { Nature of } \\
\text { Mediation }\end{array}$ \\
\hline Preview-mode & Text & $0.331^{* * *}$ & $0.143^{* * *}$ & $0.148^{*}$ & $\begin{array}{l}\text { Partial } \\
\text { mediation }\end{array}$ \\
& Audio-visual & $0.206^{* * *}$ & 0.048 & $0.189^{* *}$ & Full mediation \\
\hline $\begin{array}{l}\text { Testimonial- } \\
\text { type }\end{array}$ & Positive & $0.238^{* * *}$ & $0.116^{* *}$ & $0.125^{*}$ & $\begin{array}{l}\text { Partial } \\
\text { mediation }\end{array}$ \\
\hline Advertisement- & $\begin{array}{l}\text { Company- } \\
\text { dependent }\end{array}$ & $0.127^{*}$ & 0.056 & $0.186^{* *}$ & $\begin{array}{l}\text { Partial } \\
\text { mediation }\end{array}$ \\
\hline $\begin{array}{l}\text { Company- } \\
\text { neutral }\end{array}$ & $0.308^{* * *}$ & $0.184^{* * *}$ & $0.133^{*}$ & $\begin{array}{l}\text { Partial } \\
\text { Mediation }\end{array}$ \\
\hline
\end{tabular}

Note: $\quad{ }^{* * *} \mathrm{p}<0.001,{ }^{* *} \mathrm{p}<0.01,{ }^{*} \mathrm{p}<0.05,($ Two tailed)

$\mathrm{PQ}$ - perceived quality; Intention - intention to apply; Mediator- organizational attractiveness

Table 2: Moderated mediation results for perceived organizational attractiveness across different design manipulations of online job advertisement on the association between perceived quality of online job advertisements and applicant's intention to apply

However, the indirect effect of the partial mediation with the realistic employee testimonials (indirect $\beta=0.186, \mathrm{p}<0.01$ ) was greater than the website with positive testimonial (indirect $\beta=0.125, \mathrm{p}<0.05)$. However, hypothesis 5 a did not receive support since there was no change in the type of mediation. Hence, we got indication that the type of employee testimonial did not matter for website quality perception. As for the source of job advertisement, we received support for hypothesis6a since the nature of mediation changed from full to partial. The indirect effect for the website with company-dependent advertisement (indirect $\beta=0.075$, $\mathrm{p}<0.05$ ) was less than the featuring company neutral blog-based advertisement (indirect $\beta=$ $0.133, \mathrm{p}<0.05)$, which indicated that blogs may be better suited for influencing job-seekers' intention to apply. Table 3 demonstrates the moderated mediation analysis with respect to perceived job advertisement credibility, organizational attractiveness and intention to apply. From table 3, it follows that all the three website modifications exert moderated mediation effect on the relationship between the above-mentioned variables.

Therefore, hypotheses $4 \mathrm{~b}, 5 \mathrm{~b}$ and $6 \mathrm{~b}$ all received support. On closer inspection, the indirect effect for website with realistic employee testimonials (indirect $\beta=0.558, \mathrm{p}<0.001$ ) is distinctly higher than website with positive testimonial (indirect $\beta=0.492, p<0.001$ ), which indicates that RJP based employee testimonials were appraised more favourably than only positively framed ones. This provides support for our argument that realistic employee testimonials may be better suited to evoke credibility feeling in the job-seekers' mind. It is also observed that in case of the website with advertisement featured through blog, the mediating effect (indirect $\beta$ $=0.589, \mathrm{p}<0.001)$ is considerably higher than the company website featured advertisement (indirect $\beta=0.514, p<0.001$ ). For the preview-mode manipulation, the difference in indirect effect is not encouraging. This indicates that preview-mode does not create any notable effect on credibility perception. 


\begin{tabular}{llcccc}
\hline $\begin{array}{l}\text { Design } \\
\text { Manipulations }\end{array}$ & $\begin{array}{l}\text { Level of } \\
\text { Moderation }\end{array}$ & $\begin{array}{c}\text { Perceived Credibility } \rightarrow \text { Organizational Attractiveness } \rightarrow \text { Intention to Apply } \\
\text { PC } \rightarrow \text { Intention } \\
\text { (without } \\
\text { mediator OA) }\end{array}$ & $\begin{array}{c}\text { PC } \rightarrow \text { Intention } \\
\text { (with mediator } \\
\text { OA) }\end{array}$ & $\begin{array}{c}\text { Total Indirect } \\
\text { Effect }(\beta)\end{array}$ & $\begin{array}{c}\text { Nature of } \\
\text { Mediation }\end{array}$ \\
\hline Preview-mode & Text & $0.566^{* * *}$ & 0.042 & $0.524^{* *}$ & Full mediation \\
& Audio-visual & $0.664^{* * *}$ & $0.261^{* * *}$ & $0.529^{* *}$ & $\begin{array}{l}\text { Partial } \\
\text { mediation }\end{array}$ \\
\hline $\begin{array}{l}\text { Testimonial- } \\
\text { type }\end{array}$ & Positive & $0.238^{* * *}$ & $0.116^{* *}$ & $0.492^{* *}$ & $\begin{array}{l}\text { Partial } \\
\text { mediation }\end{array}$ \\
\hline $\begin{array}{l}\text { Rdvertisement- } \\
\text { source }\end{array}$ & $\begin{array}{l}\text { Company- } \\
\text { dependent } \\
\text { Company- } \\
\text { neutral }\end{array}$ & $0.719^{* * *}$ & $0.169^{* *}$ & $0.514^{* *}$ & $\begin{array}{l}\text { Partial } \\
\text { mediation }\end{array}$ \\
\hline
\end{tabular}

Note: ${ }^{* * *} \mathrm{p}<.001,{ }^{* *} \mathrm{p}<.01,{ }^{*} \mathrm{p}<.05$ (Two-tailed)

PC- perceived credibility; Intention - intention to apply; Mediator- Organizational Attractiveness

Table 3: Moderated mediation results for perceived organizational attractiveness acrossdifferent design manipulations of online job advertisement on the association between perceived credibility of online job advertisements and applicant's intention to apply

\section{Discussion}

The findings provide strong support for our proposed relational model. It is observed that jobseekers' perception about website quality is influenced by the use of attractive audio-visual rather than through plain text description. A glimpse of the internal work culture possibly increases their interest in the employer. This subsequently increases their intention to apply for jobs posted by firms which advertise their workplace environment innovatively. It is also observed that employee testimonials highlighting both pros and cons of a firm are viewed as more believable and such testimonials can enhance the perceived credibility of online job advertisements; since job-seekers get the signal that the potential employers are not sugarcoating the opportunity to work for them. Finally, it is observed that online job advertisements linked with external employee review blogs increases the credibility of the advertisement and enhances the perceived attractiveness of the employer in the mind of the job-seekers. Specifically, if corporate recruiters link their career web-pages with external employee review blogs such as Glassdoor, then such an arrangement may be viewed as an honest effort by the employer to project what their organization is really about.

\subsection{Managerial and societal implication}

The future of labour market across countries is going to be skewed in such a manner that in certain countries, the working age population will continue to decline (e.g., Japan) while in some others, there is going to be an abundance of youth (e.g., China and India) in the coming decades (United Nations World Population Prospect, 2010). For instance, India is a country with a huge youth population as per the 2010 report by United Nations World Population Prospects (UNDP), but, as of now, there is more supply of labour than it is required. On the other hand, countries like Japan are going to face huge labour shortage in near future due to its ageing population (UNDP, 2010). This is going to posit a scenario, where countries facing population decline will rely on global workforce to fill up the future vacancies. In this endeavour, they will have to strongly rely on online recruitment as a medium of talent 
attraction, since the global workforce is geographically spread out across the world. Under such circumstances, the websites of the firms of such countries will be the very first line of contact between the firms and potential candidates. Another important development in near future is going to be the reshaping of traditional job role itself. The job market is already beginning to observe the phenomena such as crowd-sourcing, freelancing and jigs replacing more conventional direct payroll jobs. Gradually, future jobs are going to shift to a more contractual type model, and in such a scenario, traditional recruitment channels will give way to social media recruiting, recruiting on the Twitter and through virtual worlds such as Second-life (Russel, 2008). This increase in web-based recruitment is going to be a certainty as per industry experts (Walker et al., 2010). Hence, considering the changing dynamics of global workforce, our research in this area will add value to existing practitioner knowledge.

\subsection{Limitations and future directions}

This study provides empirical support regarding the impact that Web 2.0 tools may have in addressing the problem of low credibility associated with e recruitment channels. However, since the study is experimental in nature, the lack of external validity is a limitation for this paper. Further empirical validation of the same is required for strengthening the findings in this article. While the existing theoretical and empirical evidence do point towards the requirement for use of RJPs and blogs in online career web-pages, it may not be absolutely mandatory since ' job' as product has its unique appeal that is missing in traditional products and services. Often jobseekers may overlook such cues if they are in desperate need for employment and all they want is a job. It is only when a sustainable talent acquisition issue arises supplemented by shortage of adequate skilled workers that the issue of talent attraction and competition to hire the best will arise. Hence the framework may not be applicable in a labour market, where job is a crisis.

\section{Conclusion}

This study highlights the role of web 2.0 technologies on attracting the right talent from the vast Indian labour market which can reduce delay in sourcing candidates and also help in quality hiring. Specifically, this study Firms need to leverage on podcast technology to highlight their workplace, post their virtual workplace tours through their official YouTube page and showcase the same through their website. The present study provides empirical support for incorporating this feature in corporate career websites. Another point to note is that job-seekers who use e-recruitment extensively are mostly from the millennial generation (Walker et al., 2009). This generation is more internet savvy than previous cohorts and they are more likely to leverage the potential of online recruitment. It is also more probable that online job-seekers will do their own background search about potential employers before applying for jobs. One likely source of getting such information can be through blogs and forums such as Glassdoor and Quora (Mallon, 2017; Thomas, 2017). Glassdoor, an online platform for hosting job and company related information, features over 35 million employee reviews, while Quora has a footfall of 190 million users per month. In our study, it is empirically shown that job-seekers value advertisements presented through blogs which do not have any apparent connection with the firm. Information posted through such platforms trigger more trust in the minds of the job-seekers and this leads to increased inclination towards applying for jobs posted through company neutral platforms. 
This study further validates that RJPs can also play a crucial role in enhancing the credibility of the recruitment message and this type of communication needs to be further explored. However, there may be issues regarding the extent to which neutral platforms can ensure the credibility of the information posted through such channels. For example, what if anonymous reviewers post malicious and fraudulent content out of some personal grudge against any employer? The solution to nullify such event lies in the degree to which third party job-blogs would go to authenticate identity of a user and in their readiness to take legal actions against those who misuse the forum. Glassdoor provides a detailed list of its responsibilities and vigilance to keep any unhealthy discussion off their blog space through their privacy policies and terms and conditions. Future business ventures should keep such intricacies in mind if they wish to appeal to credibility perceptions of job-seekers in proper light.

\section{References}

Aaker, J. L. (1997). Dimensions of brand personality. Journal of Marketing Research, 34, 347-356.

Adapa, S., \& Cooksey, R. (2013). Factors affecting consumer's continued use of Internet banking: Empirical Evidence from Australia. Australasian Journal of Information Systems, 18(1), 5-31.

Ajzen, I. (1991). The theory of planned behavior. Organizational Behavior and Human Decision Processes, 50(2), 179-211.

Allen, D. G., Mahto, R. V., \& Otondo, R. F. (2007). Web- based recruitment: Effects of information, organizational brand, and attitudes toward a web site on applicant attraction, Journal of Applied Psychology, 92(6), 1696-1708.

Ambler, T., \& Barrow, S. (1996). The employer brand. Journal of Brand Management, 4(3), 185206.

Banerjee, P. (2016). Attracting Job-Seekers through Online Job Advertisements: Application of RJPs, Blogs and Video Podcasts. International Journal of Technology and Human Interaction, 12(3), 1-17.

Banerjee, P., \& Gupta, R. (2016). Design deficiencies in corporate career web-sites in India: A content analysis. Human Systems Management, 35(4), 291-300.

Barksdale Jr, H. C., Bellenger, D. N., Boles, J. S., \& Brashear, T. G. (2003). The impact of realistic job previews and perceptions of training on sales force performance and continuance commitment: A longitudinal test. Journal of Personal Selling \& Sales Management, 23(2), $125-138$.

Barnes, S. J., \& Vidgen, R. T. (2002). An integrative approach to the assessment of e-commerce quality. Journal of Electronic Commerce Research., 3(3), 114-127.

Bewsell, G. R. (2009). Online trust mechanisms: a domain study of online auctions. Australasian Journal of Information Systems, 15(2), 149-167.

Borstorff, P. C., Marker, M. B., \& Bennett, D. S. (2007). Online recruitment: Attitudes and behaviors of job seekers. Journal of Strategic E-commerce, 5(1/2), 1.

Breaugh, J. A., \& Starke, M. (2000). Research on employee recruitment: So many studies, so many remaining questions. Journal of Management, 26(3), 405-434. 
Cable, D. M., Aiman-Smith, L., Mulvey, P. W., \& Edwards, J. R. (2000). The sources and accuracy of job applicants' beliefs about organizational culture. Academy of Management Journal, 43(6), 1076-1085.

Cable, D. M., \& Yu, K. Y. T. (2006). Managing job seekers' organizational image beliefs: The role of media richness and media credibility. Journal of Applied Psychology, 91(4), 828.

Cable, D. M., \& Yu, K. Y. T. (2007). How selection and recruitment practices develop the beliefs used to assess fit. In Perspectives on Organizational Fit, 155-182.

Chandler, P., \& Sweller, J. (1991). Cognitive load theory and the format of instruction. Cognition and Instruction, 8(4), 293-332.

Chapman, D. S., \& Webster, J. (2003). The use of technologies in the recruiting, screening, and selection processes for job candidates. International Journal of Selection and Assessment, 11(2-3), 113-120.

Chatterjee, S. R. (2007). Human resource management in India: 'where from' and 'where to?'Research and Practice in Human Resource Management, 15(2), 92-103.

Cober, R. T., Brown, D. J., \& Levy, P. E. (2004). Form, content, and function: An evaluative methodology for corporate employment web sites, Human Resource Management, 43(2/3), 201-218.

Daft, R. L., \& Lengel, R. H. (1986). Organizational information requirements, media richness and structural design. Management science, 32(5), 554-571.

De Goede, M. E., Van Vianen, A. E., \& Klehe, U. C. (2011). Attracting applicants on the web: PO fit, industry culture stereotypes, and website design. International Journal of Selection and Assessment, 19(1), 51-61.

Dineen, B. R., Ash, S. R., \& Noe, R. A. (2002). A web of applicant attraction: Personorganization fit in the context of web-based recruitment, Journal of Applied Psychology, 87 (4), 723-734

Doh, J.P., Stumpf, S.A., Tymon, W. \& Haid, M. (2008). How to retain talent in India? MIT Sloan Review, 50 (1), 5-7.

Dugoni, B.L., \& Ilgen, D.R. (1981). Realistic job previews and the adjustment of new employees. Academy of Management Journal, 24(3), 579-591.

Edwards, J. R., \& Lambert, L. S. (2007). Methods for integrating moderation and mediation: a general analytical framework using moderated path analysis. Psychological Methods, 12(1), 1.

Fisher, C.D., Ilgen, D.R., \& Hoyer, W.D. (1979). Source credibility, information favorability and job offer acceptance. Academy of Management Journal, 22(1), 94-103.

Forder, P. M., Gebski, V. J., \& Keech, A. C. (2005). Allocation concealment and blinding: when ignorance is bliss. Medical Journal of Australia, 182(2), 87-89.

Gokhale, P.A., \& Chandra, S. (2009). Web 2.0 and e learning: the Indian perspective. DESIDOC Journal of Library and Information Technology, 29 (1), 5-13. 
Gregory, C. K., Meade, A. W., \& Thompson, L. F. (2013). Understanding internet recruitment via signaling theory and the elaboration likelihood model. Computers in Human Behavior, 29(5), 1949-1959.

Hair, J.F., Anderson, R.E., Tatham, R.L., \& Black, W.C. (1998). Multivariate data analysis (5th Ed.). Prentice Hall.

Highhouse, S., Hoffman, J. R., Greve, E. M., \& Collins, A. E. (2002). Persuasive impact of organizational value statements in a recruitment context. Journal of Applied Social Psychology, 32(8), 1737-1755.

Howardson, G. N., \& Behrend, T. S. (2014). Using the Internet to recruit employees: Comparing the effects of usability expectations and objective technological characteristics on Internet recruitment outcomes. Computers in Human Behavior, 31, 334-342.

Hu, L. T., \& Bentler, P. M. (1999). Cutoff criteria for fit indexes in covariance structure analysis: Conventional criteria versus new alternatives. Structural Equation Modeling: A Multidisciplinary Journal, 6(1), 1-55.

India's best companies to work for: The complete list (2017). ET Bureau, 3rd July, 2017. Available at: https://economictimes.indiatimes.com/news/company/corporatetrends/indias-best-companies-to-work-for-2017-the-completelist/articleshow/59419981.cms(accessed on: 3rd December, 2017, 12:45 pm)

Johnson, T. J., \& Kaye, B. K. (2004). Wag the blog: How reliance on traditional media and the Internet influence credibility perceptions of weblogs among blog users. Journalism $\mathcal{E}$ Mass Communication Quarterly, 81(3), 622-642.

Jöreskog, K. G. (1993). Testing structural equation models. In K. A. Bollen\& J. S. Lang (Eds.)Testing structural equation models (pp.294-316). Newbury Park, CA: Sage.

Knight, S. A., \& Burn, J. M. (2011). A preliminary introduction to the OTAM: Exploring users' perceptions of their on-going interaction with adopted technologies. Australasian Journal of Information Systems, 17(1), 5-41.

Koong, K. S., Liu, L. C., \& Williams, D. L. (2002). An identification of Internet job board attributes. Human Systems Management, 21(2), 129-135.

Koufaris, M. (2002). Applying the technology acceptance model and flow theory to online consumer behavior. Information Systems Research, 13(2), 205-223.

Kumari, G., Bhat, J., \& Pandey, K. M. (2010). Recruitment and Selection Process: A Case Study of Hindustan Coca-Cola Beverage Pvt. Ltd, Gangyal, Jammu, India. International Journal of Innovation, Management and Technology, 1(4), 441.

Lim, W. M. (2018). Dialectic Antidotes to Critics of the Technology Acceptance Model: Conceptual, Methodological, and Replication Treatments for Behavioral Modeling in Technology-Mediated Environments. Australasian Journal of Information Systems, 22, 1-11.

Lin, H-F. (2010). Applicability of the extended theory of planned behavior in predicting job seeker intentions to use Job-search websites. International Journal of Selection and Assessment, 18 (1), 64-74.

Loiacono, E. T., Watson, R. T., \& Goodhue, D. L. (2007). WebQual: An instrument for consumer evaluation of web sites. International Journal of Electronic Commerce, 11(3), 51-87. 
Lowry, P. B., \& Gaskin, J. (2014). Partial least squares (PLS) structural equation modeling (SEM) for building and testing behavioral causal theory: When to choose it and how to use it. IEEE Transactions on Professional Communication, 57(2), 123-146.

Maurer, S.D., \& Liu, Y. (2007). Developing effective e-recruiting websites: Insights for managers from marketers. Business Horizons, 50, 305- 314.

Maurer, S. D., \& Cook, D. P. (2011). Using company web sites to e-recruit qualified applicants: A job marketing-based review of theory-based research. Computers in Human Behavior, 27(1), 106-117.

McGowan, M.K. (2010). The Unexplored New Medium: Recent Trends in Podcast Advertising. The Elon Journal of Undergraduate Research in Communications, 1 (2), 97-111.

Meglino, B.M., Ravlin, E.C. \& Denisi, A.S. (1997). When does it hurt to tell the truth? The effect of realistic job previews on employee recruiting. Public Personnel Management, 26 (3), 413422.

Mallon, D. (2017). Thanks to the 'Glassdoor Effect,' companies will never be the same. Available at: https://www.benefitnews.com/opinion/thanks-to-the-glassdoor-effectcompanies-will-never-be-the-same

Monster Employment Index (2017). Available at: http://media.monsterindia.com/logos/mei/moin/MEI_IN_Dec17.pdf

Naukri Job Speak (2017). Available at: http://www.infoedge.in/pdfs/jobspeak-report-april2017.pdf

Ng, K. Y., Ang, S., \& Chan, K. Y. (2008). Personality and leader effectiveness: a moderated mediation model of leadership self-efficacy, job demands, and job autonomy. Journal of Applied Psychology, 93(4), 733.

Nunnally, J. C. (1978). Psychometric theory (2nd ed.). New York: McGraw-Hill.

Oskamp, S. (1977). Attitudes and opinions. Prentice Hall, Englewood Cliffs, N.J.

Petty, R.E., Kasmer, J., Haugtvedt, C. \& Cacioppo, J. (1987). Source and message factors in persuasion: A reply to stiff's critique of the elaboration likelihood model. Communication Monographs, 54 (3), 233-249.

Pfieffelmann, B., Wagner, S. H., \&Libkuman, T. (2010). Recruiting on corporate web sites: Perceptions of fit and attraction. International Journal of Selection and Assessment, 18(1), 4047.

Phillips, J. M. (1998). Effects of realistic job previews on multiple organizational outcomes: a meta-analysis. Academy of Management Journal, 41 (6), 673-690.

Popovich, P., \& Wanous, J. P. (1982). The realistic job preview as a persuasive communication. Academy of Management Review, 7(4), 570-578.

Preacher, K. J., Rucker, D. D., \& Hayes, A. F. (2007). Addressing moderated mediation hypotheses: Theory, methods, and prescriptions. Multivariate Behavioral Research, 42(1), 185-227.

Reeve, C. L., Highhouse, S., \& Brooks, M. E. (2006). A closer look at reactions to realistic recruitment messages. International Journal of Selection and Assessment, 14(1), 1-15. 
Russell, J. (2009). Web 2.0 technology: how is it impacting your employer brand? Nursing Economics, 27(5), 335.

Saks, A. M., \& Cronshaw, S. F. (1990). A process investigation of realistic job previews: Mediating variables and channels of communication. Journal of Organizational Behavior, 11(3), 221-236.

Silverthorne, C. P., \& Mazmanian, L. (1975). The effects of heckling and media of presentation on the impact of a persuasive communication. The Journal of Social Psychology, 96(2), 229236.

Thomas, A. (2017). Quora raises $\$ 85$ million, the Q\&A platform is now a Unicorn. Available at: https://economictimes.indiatimes.com/small-biz/money/quora-raises-85-million-theqa-platform-is-now-a-unicorn/articleshow/58313275.cms

Tyagi, A. (2012). Effective talent acquisition through e recruitment: a study. EXCEL International Journal of Multidisciplinary Management Studies, 2(1), 148-156.

United Nations World Population Prospect (2010), available at: http://esa.un.org/wpp/ExcelData/population.htm (accessed on 14.01.2011).

Van Hoye, G., \& Lievens, F. (2007). Investigating web-based recruitment sources: Employee testimonials vs word-of-mouse. International Journal of Selection and Assessment, 15(4), 372-382.

Van Birgelen, M. J., Wetzels, M. G., \& van Dolen, W. M. (2008). Effectiveness of corporate employment web sites: How content and form influence intentions to apply. International Journal of Manpower, 29(8), 731-751.

Vicknair, J., Elkersh, D., Yancey, K., \& Budden, M. C. (2010). The use of social networking websites as a recruiting tool for employers. American Journal of Business Education, 3(11), 7 .

Walker, H. J., Feild, H. S., Giles, W. F., Armenakis, A. A., \& Bernerth, J. B. (2009). Displaying employee testimonials on recruitment web sites: Effects of communication media, employee race, and job seeker race on organizational attraction and information credibility. Journal of Applied Psychology, 94(5), 1354.

Yoon Kin Tong, D., \& Sivanand, C. N. (2005). E-recruitment service providers review: International and Malaysian. Employee relations, 27(1), 103-117.

Copyright: @ 2019 Banerjee \& Gupta. This is an open-access article distributed under the terms of the Creative Commons Attribution-NonCommercial 3.0 Australia License, which permits non-commercial use, distribution, and reproduction in any medium, provided the original author and AJIS are credited. 
Australasian Journal of Information Systems

2019, Vol 23, Research on the Role of Tech in Workforce Mgt
Banerjee \& Gupta

Talent Attraction through Online Recruitment

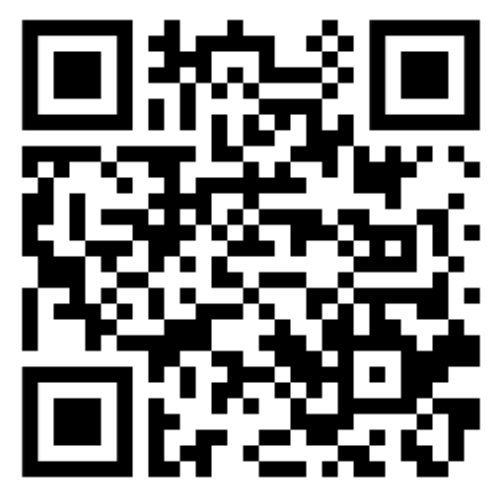

